\title{
Deciduous Oak Forests Database of the Italian Peninsula
}

\author{
Laura Cancellieri, Bruno Paura, Andrea Catorci, Maurizio Cutini \& Leonardo Rosati
}

\begin{abstract}
The existence of large databases is fundamental to improve ecological and phytogeographical information to build a 'natural' syntaxonomic scheme. In different parts of Europe, deciduous forests have already been well studied and their phytosociological meaning interpreted at regional level, nevertheless a broader scale approach is often missing. To define the thermophilic and mesophilic oak deciduous forests of Southern Europe there are several syntaxonomical proposals at higher ranks, that show differences in their ecological significance. Several Authors use the Querco-Fagetea class by which the differences between oak, mixed and beech forests are expressed at the level of order and alliance. Despite the clear link between the Italian and Balkan Peninsula, the Apennines maintain strong links with the forest vegetation of Central Europe, interpretable only within the QuercoFagetea class. In Italy phytosociological studies focused on deciduous oak forests have a relative recent tradition compared with other countries. In particular there are a great number of local contributions, while there are only few contributions that tackle syntaxonomical issues at a broader, peninsular level. For these reasons the aim of this database is to collect relevés of oak forests belonging to the Quercetalia pubescenti-petraeae and Fagetalia sylvaticae orders to perform numerical analyses and classification. Thermophilous and thermo-mesophilous oak forests are dominated by various species such as Quercus cerris, Q. pubescens, $Q$. frainetto, Carpinus betulus, Carpinus orientalis, Ostrya carpinifolia, Fraxinus ornus and Acer opalus obtusatum. The present project is based on selected published (and unpublished) relevés recorded according to the Braun-Blanquet approach and stored in a TURBOVEG database. At present 1,600 relevés of oak forests vegetation surveyed in Peninsular Italy are stored in the Deciduous Oak Forests Database of the Italian Peninsula (GIVD ID EU-IT-006). The future goals are to determine whether the variation in species composition follows a geographical pattern, to test the real ecological characteristics of the associations recognised by phytosociological studies and to identify which diagnostic species can be used for different types.
\end{abstract}

Keywords: Fagetalia sylvaticae; phytogeography; Quercetalia pubescenti-petraeae; syntaxonomy.

\section{Deciduous Oak Forests Database of Italian Peninsula}

Scope: We collected in our database all available phytosociological vegetation plot (published and unpublished) about deciduous oak forest vegetation in the peninsular Italy belonging to Quercetalia pubescenti-petraeae and Fagetalia sylvaticae to perform syntaxonomical revisions and phytogeographical analysis.

Status: ongoing capture

Period: 1971-2011

Database manager(s): Laura Cancellieri (cancelli@uniroma3.it); Leonardo Rosati (leonardo.rosati@unibas.it)

Owner: Laura Cancellieri, Andrea Catorci, Maurizio Cutini, Bruno Paura, Leonardo Rosati (private)

Web address: [NA]

Availability: according to a specific agreement

Online upload: no

Online search: no

Database format(s): TURBOVEG

Export format(s): MS Access, Excel, CSV file

Publication: [NA]

Plot type(s): normal plots

Plot-size range: $80-500 \mathrm{~m}^{2}$

Non-overlapping plots: 1,600

Total plot observations: 1,600

ots: 2,200

Completeness: $73 \%$

Countries: IT: $100.0 \%$

Forest: [NA] — Non-forest: [NA]

Guilds: all vascular plants: $100 \%$

Environmental data: [NA]

Performance measure(s): cover: $100 \%$

Geographic localisation: [NA]

Sampling periods: [NA]

Information as of 2012-07-12; further details and future updates available from http://www.givd.info/ID/EU-IT-006

Laura Cancellieri* (cancelli@uniroma3.it), Maurizio Cutini (cutini@uniroma3.it)

Biologia Ambientale, Universita' Roma Tre, Viale G. Marconi 4466, 00146 Roma, ITALY

Bruna Paura (fobos@unimol.it)

A.A.A., Universita’ Del Molise, Via de Sanctis, 86100 Campobasso, ITALY 
Andrea Catorci (andrea.catorci@unicam.it)

Scienze ambientali,sezione di botanica ed ecologia, università di Camerino, via Pontoni 5, 60032 Camerino, ITALY

Leonardo Rosati (leonardo.rosati@unibas.it)

Biologia, Difesa e Biotecnologie Agro-Forestali, Università degli Studi della Basilicata, viale dell'Ateneo Lucano 10, 85100 Potenza,

ITALY

*Corresponding author 